\title{
Leadership to Creativity and Management of Innovation? The Case of the "Innovation Club" in a Production Company
}

\author{
Vered Holzmann'1, Joseph Golan ${ }^{2}$ \\ ${ }^{1}$ The Leon Recanati School of Business Administration, Faculty of Management, Tel Aviv University, Tel Aviv, \\ Israel \\ ${ }^{2}$ Operation, Production \& Purchasing Division-Elop, Elbit Systems-ISTAR, Rehovot, Israel \\ Email:veredhz@post.tau.ac.il,golanj2@gmail.com
}

Received 13 December 2015; accepted 23 January 2016; published 26 January 2016

Copyright (C) 2016 by authors and Scientific Research Publishing Inc.

This work is licensed under the Creative Commons Attribution International License (CC BY).

http://creativecommons.org/licenses/by/4.0/

c) (7) Open Access

\section{Abstract}

In the current era of ongoing dynamic business developments and advancements, any company that wishes to succeed needs to sustain an innovative culture in order to keep its position in the front line of competition. However, being creative and innovative in a production and manufacturing environment is challenging due to the organizational characteristics derive from a hierarchical structure in which systematic procedures are strictly followed. In this paper, we present a model for creating a sustainable culture of creativity and innovation in a manufacturing organization and we demonstrate the use of this model in a leading production company in the defense industry. The model explains the initiation phase that motivates employees to explore new opportunities and the maintenance phase that forms a sustainable infrastructure, which are integrated into a coherent foundation for continuous improvement and excellence. The case study describes how the model was implemented in the production company and reviews the major barriers the management faced in the process of implementing a culture of innovation. We discuss the actions taken to create a supportable infrastructure to promote innovative behavior by employees and managers and analyze different aspects of innovation strategy. We conclude with reporting the results of implementing this model in the case company and with recommendations for other manufacturing and production companies aspire to be innovative.

\section{Keywords}

Innovation, Creativity, Entrepreneurship, Leadership 


\section{Introduction}

Industrial organizations usually employ a significant part of the overall processes in operation, production and manufacturing. Those organizations are characterized by solid and hierarchical organizational structure combined with systematic procedures that ensure the production of quality products. Therefore, creativity, innovation and entrepreneurship are rarely applied in this type of organizations although it is obvious that if they would have been applied the organization could have achieved a better competitive position in the business arena. This challenge is even more evident when we are dealing with traditional industrial organizations that have embraced established methodologies such as TQM (Total Quality Management), TOC (Theory of Constraints), six-sigma or lean manufacturing. Those methods are mainly aimed to achieve better quality but do not concern creativity, innovation and entrepreneurship in their wide understanding. Even though managers today realize that there is a positive relationship between innovation and business success, there is no established method to increase creativity and innovation which can be applied rapidly and sustain for many years.

In this paper we present an easy way to use technique that provides a comprehensive response to the organizational and cross-organizational processes aim to support innovation. It is based on a model that integrates leadership and management actions to create a continuous development of original ideas and making them valuable to the organization thorough an organized system of procedures and information. The rational that motivates the development of innovation is that each and every one of the employees is a valued contributor and that the outcomes that can be achieved by the "organizational crowd" are superior to the one that can be achieved by a group of experts. A specific case study is described in order to demonstrate how the technique can be easily applied and result in effective and efficient operation.

The following of the paper is structured as follows. The next section starts with a review of literature on creativity and innovation, their role in business success and especially in the industrial context, and it continues with a presentation of an integrative framework for creativity and innovation. The third section describes in details the case of the "innovation club". It introduces the organization that applies this technique, tells the story of establishing the club, and discusses the barriers to success and how they were resolved. We then analyze the case and discuss the implications of implementing similar methods in other industrial organizations. We summarize the paper with concluding remarks, comments on research limitations and suggestions for future studies.

\section{Background}

The effect of creativity and innovation on business success was studied in several contexts, leading to the conclusion that among all the impacting factors, cultural aspects and supporting organizational processes have a dominant weight [1]-[4]. Although creativity and innovation are both found to be vital for success and are interconnected in their implementation, they differ in purpose and performance. Creativity is a process that involves the discovery of new ideas or concepts. It deals with the development of novel, original, and unusual ideas that can be manifested in various ways. Creative developments are usually expressed by something tangible that can be seen, heard, felt, smelled, touched or tasted. Innovation, on the other hand, is about introducing change to an existing system in a way that will make the new idea viable and valuable. Innovation is a process in which we develop new way of doing something. It may refer to incremental or radical changes related to the products, services, or processes.

Within the business context, creativity is the production of original and novel ideas while innovation is the result of selecting the appropriate ideas and implementing them in a way that creates value to the organization. Hence, the integration of creativity and innovation is needed in order to generate a continuing platform for success. Theodore Levitt summarizes it by saying that "what is often lacking is not creativity in the idea-creating sense but innovation in the action-producing sense, i.e. putting ideas to work" ([5], p. 139). In the next two sections, we will discuss the concepts and characteristics of creativity and innovation and then we will present a model that represents the managerial perspective of integrating the two into a coherent practice.

\subsection{Creativity}

Creativity is related to four different facets: the person, the process, the product, and the situation [6]. In this context, we focus on the process of creativity that enables the generation of new ideas by exploiting opportunities. Stein [7] [8] defined creativity as "a process that results in a novel work that is accepted as useful, tenable 
or satisfying by significant group of people at some point in time” ([8], p. xi). Although the literature offers several perspectives and interpretations, this standard definition suggests that a creative work should be useful to a group of people, thus adds a societal aspect to the actual efforts involved in creating something new and by that integrates the requirements for originality and effectiveness [9]. Similar perception was presented later by other researchers (ex. [10]) [11] that provided interpretations and explanations to this process. It can be summed up by the definition of creativity by Sternberg who argued that "creativity is the ability to produce work that is both novel (i.e., original, unexpected) and appropriate (i.e., useful, adaptive concerning task constraints)” ([12], p. 3).

The ability to be creative is sometimes perceived as a trait that some people are born with while others miss. However, contemporary approach to creativity assumes that everybody has basic capacities to produce creative work in their domain and that environment can improve the level and frequency of creative behavior. Amabile identified three variables related to individual or small-group creativity: intrinsic motivation to do the task, skills in the task domain, and skills in creative thinking [13]. The model presented there includes the elements of management practices, resources, and organizational motivation in the work environment, as well as the elements of expertise, task motivation and creativity skills in the individual and team creativity domain. The relationship between the organizational work environment and the creativity of individuals and teams was further studied [14]-[17] to identify factors such as leadership, teamwork, and organizational climate as affecting factors.

The development of creativity in the workplace is important because creativity is a mandatory stage that proceeds innovation; creative ideas are used for innovation. Von Stamm (2008) described it in the following words: "If implementation is putting an idea into practice, creativity is coming up with the idea in the first place. Creativity is an essential part of innovation, is the point of departure” ([18], p. 2]. Thus, innovation should start with creativity and it is further developed with respects to the product, the business model, the organizational processes, the applied technology, or the market.

\subsection{Innovation}

The study of innovation started many years ago [19]-[21] and developed throughout the years in various directions. Traditionally, innovation strategy has been studied on four, interrelated, different dimensions: exploration vs exploitation of capabilities; market pull vs technology push; internal vs external sourcing of capabilities; and product vs process innovation.

Exploitation vs. exploration: exploitation strategy is focused on current organizational resources and capabilities, aiming to improve, to upgrade, or to enhance efficiency, while exploration strategy is focused on new products or capabilities, aiming to offer a new developed product, process, or capability [10] [22] [23].

Market pull vs Technology push: market pull is a process that starts with an identification of a need or a requirement for a new product or a solution to a problem, which comes from the market place, continues with research market or focus groups to test potential solutions, development production, and sales. Technology push is a process that starts with research \& development, continues with production and then introduces the new product to the customers. It is usually initiated when a company has new technology or capability, which is applied to a new product that is then marketed to the public, with no preliminary research market [24] [25].

Internal vs external capabilities: internal capabilities and internal strategic decisions are related to changes that a firm makes by using its existing resources in new combinations or by developing new resources by its own. The internal environment can be improved by examination the organizational value chain and identify activities that can improve the value of the product or service for the market. External capabilities and external strategic decisions are related to changes that a firm makes by trading strategic capabilities. Those changes can be achieved either by purchasing a resource or a service from another firm, by collaborating with another firm that transfer resources, skills or procedures, or by acquisition of an entire firm that owns the resources, skills or procedures [18] [26]-[28].

Product vs Process innovation: Product innovation consists of changes in the product or service attributes that a firm offers. These changes make the new product or service better than the existing ones that the firm offers to its customers; it better stratifies the customers' needs and preferences. Process innovation consists of changes in the way the product or service is produced and delivered. These changes are manifested in the production or operation processes rather than in the product or service itself [6] [29].

Other approaches are focused on the following decisions: 1) degree of innovation: incremental/radical; 2) 
stimulus for innovation: first mover/late mover; and (3) originality of the innovation: imitative/inventive [30][32].

These various aspects of innovation should all take into consideration when a company selects its innovation strategy. However, once selecting the appropriate strategy, the company needs to establish an infrastructure that will support the innovative processes. Therefore, as Peter Drucker put it: "The entrepreneurial requires different management from the existing. But like the existing it requires systematic, organized, purposeful management” ([33], p. 141). The following section presents an overview of a managerial perspective for leadership of creativity and management of innovation.

\subsection{An Integrative Framework for Creativity and Innovation}

Creativity and innovation are both required for a successful company aims to excel for a long term. Successful innovative companies are engaged with activities in the following domains: innovation, networks, internationalization, organizational learning, top management teams and governance, and growth [34]. A comprehensive framework suggests that creativity is supported by leadership while innovation is supported by management and while each one of them can achieve good immediate results, only the combination of the two enables an ongoing successful implementation that is manifested by entrepreneurial behavior, effective and efficient processes, quality products, and excellent business results. Although leadership and management are obviously related, we argue that fostering creativity requires strong leadership that encourages employees to identify opportunities and generate new ideas. These ideas will become valuable to the company if they will be managed systematically to select the ideas for implementation, to actually implement the selected ideas, to measure effectiveness and efficiency and to support employees to further identify additional opportunities.

The following Figure 1 presents the integrative framework for creativity and innovation, where leadership and management are represented by tangentially diagonal lines (leadership in green lines and management in blue lines) that cover parts of the circle, but together have full coverage of the process.

Starting with opportunity identification, organizational leaders create an environment that is characterized with trust, curiosity and tolerance of diversity [14] [16] [35]. In this type of environment, the employee constantly looks for better ways to do things and to improve the process, the product or the working environment. Leadership, defined as "a process of social influence in which a person can enlist the aid and support of others in the accomplishment of a common task" ([36], p. 5), provides the employee the confidence, lack of fear, willingness to make a change, and to take risks when generating new ideas. Transformational leadership style, in which the leader is engaged with the followers, creates a common vision to guide the change through inspiration, raises consciousness about the significance of expected outcomes and new ways to achieve those outcomes,

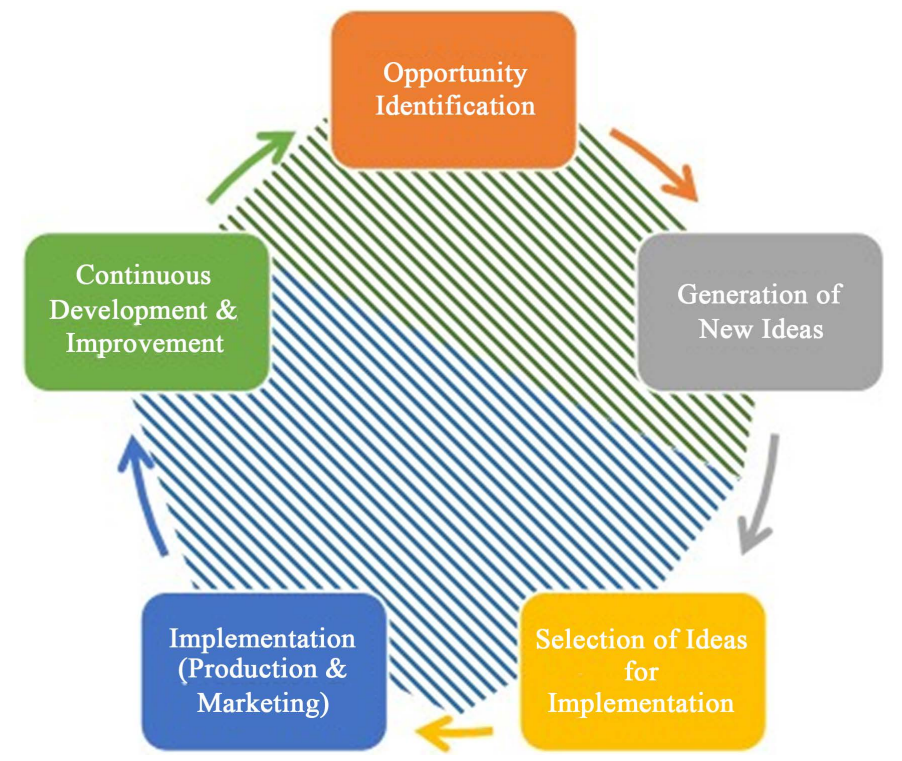

Figure 1. Integrated framework for creativity and innovation. 
and executes the changes with the committed members of the group [37] [38]. The following phase of selecting the ideas for implementation requires organized, transparent and systematic procedures that enable each one of the employees to have equal opportunity to have his/her idea selected. The structured managerial practice is crucial for the involvement of all employees in this process. An additional important aspect that empowers employees to be creative in the workplace is the confident that they will be valued for their contribution by rewards and recognition and by efficiently implementing the selected ideas. In this stage, efficient and controlled measures are needed for the execution of the creative ideas. The final step in the ongoing cycle of creativity and innovation in the workplace refers to the continuous aspect of development and improvement, which can be achieved by top management support for ongoing, continuous, processes of improvement. Top managers are leaders that act as facilitators [39] and communicate effectively on both strategic and operational levels [40].

This framework, which represents leadership for creativity and management of innovation, creates a continuous process that drives an organization to excellence, quality and entrepreneurial spirit. Although the framework can be applied in any type of organization, it is especially challenging in an industrial organization. In the high-tech industry and in R \& D establishments we are used to see innovative programs that are generated by enthusiastic researchers and risk-seeking managers. However, the working environment in an industrial, production and manufacturing companies is characterized by a solid hierarchical structure in which systemic procedures are strictly followed in order to ensure the precise production of the specified product, adhering to quality, functionality, schedule, and cost. Thus, implementing the integrated framework of creativity and innovation in this type of environment is much more demanding, but at the same time, it is usually much more rewarding.

\section{The Case of the "Innovation Club"}

\subsection{Research Method}

The "Innovation Club" is an implementation of the integrated framework of creativity and innovation, applied in an operation, production and manufacturing company. We use this case following the guidelines for case study research to explore the field and describe the events and outcomes [41] [42]. Between March 2014 and September 2015, we conducted the field research by contacting the persons who are best informed about the processes implemented in the company. We used the triangulation principle of data collection by using the combination of interviews, direct observations, and content analysis of documents. We interviewed 24 managers and employees in the company, including the CEO, VPs, team managers, professional experts, and line workers, to understand the different perspectives and interpretations of the process. The semi-structured interviews were based on a designed protocol, with a set of well-prepared set of closed and open questions and a room to develop the interview freely based on the interviewee's preferences. The interviews were carefully coded for analysis. We also visited the production and manufacturing plants in different occasions to have a direct and objective observation of the events. These observations were documented for further analysis. Finally, we received a digital copy of all the data related to the "innovation club" activity, including applications by managers and employees, as well as all the reviewers' reports. All the data collected was documented and coded for a cross-analysis by the researchers.

\subsection{The Organization}

Elbit Systems-ISTAR (Intelligence Surveillance Target Acquisition and Reconnaissance) is a leading company in the field of electro-optical and unmanned vehicle in air and marine products and systems, conducting research, development, production, and sales as well as offering support. Based in Israel, the company is a major supplier of high quality, high technology defense, scientific, and commercial electro-optical products and systems both locally and globally.

The company is one of the largest manufactures of electro-optics outside the US Since its establishment, almost 80 years ago, it has gained unique experience and special competencies, mainly thanks to close cooperation with its customers throughout the years. The company's customers include many security organizations and armies around the world. The company abilities include development and production of subassemblies and sensors as well as integration of multidisciplinary products and after sales service. The line of products includes laser systems, thermal imaging systems, head-up displays, observation systems, and optoelectronics warfare. The company operates manufacturing facilities in all technological areas required for the production of its sophisti- 
cated electro-optic equipment. This includes mainly operation in thermal imaging systems, land and airborne electro-optics and laser systems. The high level of integration between these different aspects of operation ensures thorough control over the overall production process, reliable products, and schedule compliance. The company emphasizes quality and is certified to several international quality standards.

The production and manufacturing division is responsible for the overall operations, managing the logistics chain of the company, from the acquisition of material and components through production of components and system assembling. The manufacturing plants include mechanical production plant, an optical plant, an electronic assembly plant, and administration of system assembly lines. The organization's accomplishments are achieved through the efforts of its diverse workforce, including line managers, quality engineers, technicians, inspectors, line workers, and integrators, to name but a few. All of them are involved in the activities of the "innovation club".

\subsection{Establishing a Creative and Innovative Organization}

Aspiring to enhance business, the organization management encourages and motivates employees to create products of higher quality by improving, optimizing, and innovating operational and managerial processes, which would also lead to a better working environment.

The preliminary actions taken by the management were aimed at changing the organizational culture to one that accepts and fosters innovative ideas. Since existing organizational values were based on efficiency and accuracy, this change required a transformation in employees' perception of their workplace and expected behavior. The turning point was the establishment of the "Innovation Club", which was open to all employees, but only those who took an active role in improving the workplace, processes, services or products, were admitted as members. Employees wishing to join the club were required to submit a proposal that presents a new perspective on how things may be better executed in the organization. Submitted proposals awarded their originators with "credit points", which were part of the reward system. Points were earned on a scale of one to ten for any new idea, while the main criteria was based on originality and not on the derived value that the organization may profit if and when the proposal will be implemented. The points were given for making an effort and daring rather than evaluating the expected result of the suggested new idea. Proposals were evaluated for their level of creativity, entrepreneurship, and out-of-the-box thinking. The rewarding method enabled each and every one of the employees to be a member in the "Innovation Club".

In order to institute a solid and continuous process of idea generation, the following stage of selecting the ideas for implementation was officially formed as a transparent and equitable procedure. The Innovation Club Forum, comprising representatives from all the units in the organization and from different hierarchical levels, was established. The forum meets every few weeks to discuss and evaluate proposals and to decide how many credit points each proposal should earn. The decisions of the forum are open to all employees and published in the organization media channels. An organized procedure ensures the execution of chosen ideas for implementation by a multi-disciplinary team that also explores ways by which suggestions pertaining to a single, specific unit may be adapted cross-organizationally. The innovation cycle continues with a periodical monitoring process. The implementation control involves tracking of execution by representatives of the innovation forum and professional assessment by subject matter experts. Post-implementation efficacy is evaluated by the quality team quarterly for lessons learned and continuous improvement process.

\subsubsection{Barriers to Implementation}

Creating a culture of creativity and innovation in an industrial company is not an easy task. The transformation requires managers and employees to get out of their comfort zone. A summary of the major barriers that the company faced in the process of creating this "new" culture" of creativity and innovation is presented here.

Under allocation of resources. Although the initiation of new ideas usually does not require any special resources as employees generate those ideas from the daily work processes and environment, the evaluation of each proposal does necessitate investments. In addition, some of the accepted proposals require for a significant funds for implementation even though the beneficial results might be evident only in the far future. Thus, it is difficult to present the direct and immediate connection between the investment and the revenue of innovative ideas. Due to the low marginal revenue of industrial companies, the organizational priorities aimed to increase short term ROI (return on investment) and funds needed to promote creative and innovative ideas are not availa- 
ble.

Lack of confidence by employees. Many employees, particularly those who are inexperienced and positioned in the lower hierarchical levels are concerned that their offers are not "really" new or are not good enough. Thus, they lack the confidence to propose something new to their managers without prior confirmation. Young, immature, and non-professional employees are especially afraid to fail, and their fear grows worse if they already tried once and failed.

Distrust in the "system" and especially in the rewarding mechanism. Many employees had participated in the past in different organizational initiatives aimed to improve quality, yet frequently they felt that their efforts were not adequately assessed and appreciated. Some of the employees are afraid that their successful idea will be later assigned to their managers and they will not be credited. In addition, based on previous experience, employees doubt that their contribution to the organization will be awarded and that they will be fairly rewarded, either by a tangible, financial compensation or otherwise.

Resistance to cooperate by middle managers. Middle managers in the organization are the direct managers of professional teams in a variety of fields. They are afraid from the organizational change that not only revolutionize the known priorities but also create a new environment in which junior workers can directly contact top managers by presenting proposals for new initiatives. In addition, new initiatives by employees can be interpreted unfavorably by top management because not only the employee was aware of the difficulties and challenges, but had also found a solution where the manager failed to do so. Hence, the entrepreneurial spirit in the organization might undermine the solid organizational order.

These managerial, organizational, and personal barriers set a high bar for leaders at the company who wished to transform the traditional, production-oriented workplace into an innovative environment. The organization faced challenges that require a different organizational behavior of workers, middle managers and top managers, and a new organizational culture that employs creative and innovative thinking along with defined evaluation procedures

\subsubsection{Rising above the Barriers: Leadership and Management}

The challenge was to overcome these barriers, constraints, and limitations and to foster employees' motivation for innovation while facilitating a sustainable change from the organizational perspective as a whole. Through a combination of formal and informal approaches to the encouragement and management of the innovation process, both employees and managers in the organization embraced proactive behavior and became engaged in the long-term ongoing process of cultural change in the organization. Among the strategies to produce these results, top management of the organization adopted several endeavors that are aligned with the transformational leadership style. Through a combination of formal and informal approaches, including individualized attention to each and every employee involved in the process and personal encouraging attitude by top managers, both employees and managers in the organization embraced proactive behavior and became engaged in the long-term ongoing process of cultural change in the organization.

A few champions, including social leaders and professional mentors, were the driving force to organizational change. A few champions, including social leaders and professional mentors, were the driving force to organizational change. Champions were defined as persons at any level of the organization who were leaders and who had a group of followers comprising employees, managers, or both. These champions were identified in different organizational contexts, such as subject matter experts, union leaders, or coordinators of social groups. The champions were motivated to initiate changes and offer new ideas related to their fields of interest. They were empowered as visionary leaders who can make things happen and they later facilitated the process by networking with their respective groups and helping other members by advising them in the proposal submission process.

In order to keep the spirit of creativity and entrepreneurship the employees are stimulated by competitions. Building on the very intuitive and natural desire of people to win and to be recognized as winners, the Innovation Club announced two tracks of competition: individual and plant-based. Open to all and offering an equal opportunity to both managers and employees to win, the individual competition became a key motivating factor for innovation in the organization. The plant competition aimed to stimulate middle managers to take responsibility for creating a creative and innovative working environment. The competitive playground that was created is fair, open to all and equal to all, endorsing the approach "let the best entrepreneur win". Those successful entrepreneurs are recognized as such in celebrations at special events. Individual winners, representatives of the 
winning plant, and leading participants of the Innovation Club (as per their accumulated credit points) are invited as honorary guests to an event that is led by the organization's top management.

The social-cultural change in the organization was not easy to accomplish but thanks to massive management support and the exercise of a variety of tools and techniques, this change was generally accepted in the organization.

In addition, it was decided that in order to achieve systematic innovative activities, where new initiatives are examined by a well-defined mechanism and documented to become part of the organizational body of knowledge, a dedicated information system will be developed and installed. The information system was aimed to provide a systematic platform that will facilitate the proposal submission process and make it transparent to all members of the organization. All employees have full access to the system, allowing then not only to submit proposals but also to review proposals submitted by others. In addition, the management team has access to summary reports related to submissions by individuals, plants, topics, and other categories of interest.

\subsection{Organizational Results}

The Innovation Club exists already seven years. During this period, it has instigated the submission of 5,140 proposals by 348 employees and managers. On average, every quarter 183 new proposals are submitted from which $93 \%$ are approved for implementation and only $7 \%$ are rejected. Among the approved proposals, $74 \%$ are implemented immediately or within a very short period. The remaining $26 \%$ involve a longer process of implementation, mainly due to their long-term implications or misalignment with current organizational goals. This group of proposals is nevertheless considered organizational assets that may be utilized at a later stage and is exploited according to the organization's annual work plan.

The overall improvement in quality and efficiency, which are the direct result of the Innovation Club's activities since its inception, is especially manifested in the organization's profitability. While specific profitability data is confidential and cannot be presented here, the trend of growth is evident. The organization has been showing consistent ongoing improvement in efficiency in nearly all aspects of production and supply chain, including: financial results, meeting and shortening schedules, flow of production material, utilization of production resources, and growing customer satisfaction due to improved products of higher quality delivered in shorter periods and at lower costs.

\section{Analysis \& Discussion}

The establishment of the Innovation Club and the development of a sustainable creative and innovative working environment in a production and manufacturing organization presents an interesting example to analyze key enablers for similar circumstances. The organization is characterized as a leading manufacturer of high-quality high technology defense and scientific electro-optical products and systems, which is obliged to follow definite procedures in order to provide the exact product that was ordered. In these conditions, the integration of leadership and management is crucial. The first is vital for the inspiration of creativity and motivation to explore new directions and opportunities in a confident and supportive environment. The second is essential for the establishment of a sustainable system that works according to organized methods and procedures and can ensure the long-term maintenance of the efforts.

Among the most important success factors, we can identify the following.

The relationship between transformational leadership style, which is characterized by the four I's: Idealized Influence, Inspirational Motivation, Individualized Consideration, and Intellectual Stimulation, and innovation was already investigated in several studies and found positive [38] [43]. However, in the current paper we add to the published statistical evidence, a confirmation based on a detailed description of leadership behavior that fosters creativity and innovation in an industrial organization.

Top management support for innovation was investigated by Elenkov and Manev [44] based on 468 businesses in Europe. Consistently with finding of previous studies on innovation and leadership, they found a positive and significant effect of leadership on top management impact on product/market and organizational innovations. The role of the top manager was described by Cooper as a facilitator "to set the stage-and not be an actor front and center" ([39], p. 143). To this, we will add that the top manager is also expected to define, formulate and communicate the strategy for creativity, innovation, excellence and quality hand in hand with providing the required resources and empowering the innovative employees. Effective Communication should be managed 
at both strategic and operational levels. In order to succeed with implementing innovative ideas, an effective communication-clear messages, including verbal and nonverbal signs, listening, feedbacks, etc.-must be maintained within the team, broadly in the organization, and with key stakeholders outside the organization [40].

The managerial activities related to rewarding and establishing a recognition system to incentive employees based on their contribution and to motivate them on an individual and/or group level is of great importance. Several studies report on the value of monetary (tangible) rewarding and non-monetary (intangible) rewarding as motivation factors for contribution [45]. Although the studies were conducted in different scenes such as open innovation communities [46], healthcare [47] or product development [48], they all recognize the impact of compensation on motivation to initiate weather financially or psychologically. We reaffirm this understanding with evidence of effective innovation process in a production and manufacturing environment where the innovators are compensated with intangible rewards and are still motivated to continue contribute to the organization due to recognition and personal supporting attitude by top management.

The role of communication in business success is well-known (ex. [49]) and its vital function in the process of promoting innovation is evident [50] [51]. In this paper, we extend the role of communication as a facilitator to creativity and innovation by emphasizing the effect of open and honest communication on creativity on one hand and the effect of systematic supporting information system on innovation on the other hand. The combination of these to complementary aspects of information and communication provides a practical environment for development of new ideas and implementation of valuable initiatives. The supporting information system not only ensures a systematic process, but also enables documentation, archiving, and retrieval of all relevant information throughout the process and it creates an efficient method to transform creative ideas into organizational assets.

The industry of manufacturing and production raises a special challenge for creativity, innovation and entrepreneurship. Therefore, literature on implementing an innovation in industrial companies is limited. Available studies report on research regarding the interpretation given by top managers to different aspects of innovation in this type of organizations [45] [52], origin of innovation [53] or examination of the innovation process which is generated by top management or by the customer [54]. This study provides an in-depth examination of implementing a culture of creativity, innovation, entrepreneurship, quality and excellence in an industrial company. It suggests that applying a "partnership innovation" method within an organization can lead to extremely successful results. In this method, all employees are perceived as partners of the organization. The successful organizational change occurred not only due to the acceptance of new values, but also thanks to the comprehensive process, that everybody can and is taking part in. The concept of "crowd-wisdom" is practiced within the realm of the organization and is used by involving all employees and managers in the challenge of making better product, process, or working place. Instead of having a group of experts, opinions and ideas are collected from all employees, thus generating fruitful collective thinking environment that generates more and better achievements.

\section{Conclusions}

The relationship between innovation and business success is of special importance in the present-day dynamic arena. This understanding is common now-days and many organizations are trying to develop originality, creativeness and inventiveness. However, the implementation of these concepts in an industrial company is raising several challenges derived from the characteristics of this type of organizations. The current paper presents an extraordinary successful case study of implementing a culture of creativity and innovation in a production and manufacturing organization. It describes how leadership and management are both utilized to advance an organizational change that can sustain for the long-run and continue producing value to the organization.

We recommend managers in industrial organizations to develop and "Innovation Club" in their organizations. The implementation should follow exactly the same process as described in this paper, but the significant elements are highly recommended. It is important to brand the Innovation Club as prestigious unit either by using organizational champions as informal leaders or by any other technique. It is important to create a supportive working environment that cherish employees and managers for their innovativeness and does not punish them for failing. It is also important to establish a systematic and transparent infrastructure that will continue to support these initiatives and transform it from a one-time successful endeavor to an ongoing sustainable frame.

The current study is not free of limitations. We base our conclusions on a specific case that describes one in- 
dustrial company. As all other case studies and in general qualitative research, generalization for broad inferences is controversial and susceptible to misleads. In this specific case, the company is a large manufacture of electro-optics, operating mainly in the defense-industry, which might imply that the quality standards applied in this company are relatively high. Thus, it might not consider representative case. Nevertheless, this study is based on a comprehensive examination of the situation using three different research methods and it reports on a mature operation that exists for several years now.

Future research that will compare different implementations of applying innovation culture in industrial organizations might enrich the conclusions. Comparisons of additional methods and techniques can yield additional insights on the important factors influencing creativity and innovation in production and manufacturing companies. Another direction for further research can be the investigation of relationships between creativity, innovation, entrepreneurship and quality in industrial organizations.

\section{Acknowledgements}

The authors thank the Eli Hurvitz Institute of Strategic Management in Tel Aviv University for the support in this study.

\section{References}

[1] Heunks, F.J. (1998) Innovation, Creativity and Success. Small Business Economics, 10, 263-272. http://dx.doi.org/10.1023/A:1007968217565

[2] Rosenbusch, N., Brinckmann, J. and Bausch, A. (2011) Is Innovation Always Beneficial? A Meta-Analysis of the Relationship between Innovation and Performance in SMEs. Journal of Business Venturing, 26, 441-457. http://dx.doi.org/10.1016/j.jbusvent.2009.12.002

[3] Laforet, S. and Tann, J. (2006) Innovative Characteristics of Small Manufacturing Firms. Journal of Small Business and Enterprise Development, 13, 363-380. http://dx.doi.org/10.1108/14626000610680253

[4] West, M. and Sacramento, C.A. (2012) Creativity and Innovation: The Role of Team and Organizational Climate. In: Mumford, M., Ed., Handbook of Organizational Creativity, Academic Press, London, 359-386. http://dx.doi.org/10.1016/B978-0-12-374714-3.00015-X

[5] Levitt, T. (2002) Creativity Is Not Enough. Harvard Business Review, 80, 137-145.

[6] Brown, R.T. (2013) Creativity: What Are We Measure? In: Glover, J.A., Ronning, R.R. and Reynolds, C., Eds., Handbook of Creativity, Springer Science \& Business Media, Berlin, 3-32.

[7] Stein, M.I. (1953) Creativity and Culture. Journal of Psychology, 36, 311-322. http://dx.doi.org/10.1080/00223980.1953.9712897

[8] Stein, M.I. (2014) Stimulating Creativity: Individual Procedures. Vol. 1, Academic Press, New York.

[9] Runco, M.A. and Jaeger, G.J. (2012) The Standard Definition of Creativity. Creativity Research Journal, 24, 92-96. http://dx.doi.org/10.1080/10400419.2012.650092

[10] Shneiderman, B. (2007) Creativity Support Tools: Accelerating Discovery and Innovation. Communications of the ACM, 50, 20-32. http://dx.doi.org/10.1145/1323688.1323689

[11] Chen, M.H. (2006) Understanding the Benefits and Detriments of Conflict on Team Creativity Process. Creativity and Innovation Management, 15, 105-116. http://dx.doi.org/10.1111/j.1467-8691.2006.00373.x

[12] Sternberg, R.J. (1999) Handbook of Creativity. Cambridge University Press, Chicago.

[13] Amabile, T.M. (1988) A Model of Creativity and Innovation in Organizations. Research in Organizational Behavior, 10, 123-167.

[14] Woodman, R.W., Sawyer, J.E. and Griffin, R.W. (1993) Toward a Theory of Organizational Creativity. Academy of Management Review, 18, 293-321.

[15] Scott, S.G. and Bruce, R.A. (1994) Determinants of Innovative Behavior: A Path Model of Individual Innovation in the Workplace. Academy of Management Journal, 37, 580-607. http://dx.doi.org/10.2307/256701

[16] Amabile, T.M., Conti, R., Coon, H., Lazenby, J. and Herron, M. (1996) Assessing the Work Environment for Creativity. Academy of Management Journal, 39, 1154-1184. http://dx.doi.org/10.2307/256995

[17] Aslani, A., Helo, P. and Naaranoja, M. (2012) Development of Creativity in Concurrent Engineering Teams. American Journal of Industrial and Business Management, 2, 77-84. http://dx.doi.org/10.4236/ajibm.2012.23010

[18] Von Stamm, B. (2008) Managing Innovation, Design and Creativity. 2nd Edition, John Wiley \& Sons, Hoboken. 
[19] Marquis, D.G. (1969) The Anatomy of Successful Innovations. Innovation, 1, 28-37.

[20] Mansfield, E. (1968) Industrial Research and Technological Innovation: An Econometric Analysis. Norton, New York.

[21] Robertson, T.S. (1967) The Process of Innovation and the Diffusion of Innovation. The Journal of Marketing, 63, 1419. http://dx.doi.org/10.2307/1249295

[22] Danneels, E. (2000) The Dynamics of Product Innovation and Firm Competences. Academy of Management Proceedings, 2000, D1-D6. http://dx.doi.org/10.5465/apbpp.2000.5438540

[23] Benner, M.J. and Tushman, M.L. (2003) Exploitation, Exploration, and Process Management: The Productivity Dilemma Revisited. Academy of Management Review, 28, 238-256.

[24] Di Stefano, G., Gambardella, A. and Verona, G. (2012) Technology Push and Demand Pull Perspectives in Innovation Studies: Current Findings and Future Research Directions. Research Policy, 41, 1283-1295. http://dx.doi.org/10.1016/j.respol.2012.03.021

[25] Maital, S. and Seshadri, D.V.R. (2012) Innovation Management. Sage, New Delhi.

[26] Birkinshaw, J., Hamel, G. and Mol, M.J. (2008) Management Innovation. Academy of Management Review, 33, 825845. http://dx.doi.org/10.5465/AMR.2008.34421969

[27] Camisón, C. and Villar-López, A. (2014) Organizational Innovation as an Enabler of Technological Innovation Capabilities and Firm Performance. Journal of Business Research, 67, 2891-2902. http://dx.doi.org/10.1016/j.jbusres.2012.06.004

[28] Cassiman, B. and Veugelers, R. (2006) In Search of Complementarity in Innovation Strategy: Internal R\&D and External Knowledge Acquisition. Management Science, 52, 68-82. http://dx.doi.org/10.1287/mnsc.1050.0470

[29] Adner, R. and Levinthal, D. (2001) Demand Heterogeneity and Technology Evolution: Implications for Product and Process Innovation. Management Science, 47, 611-628. http://dx.doi.org/10.1287/mnsc.47.5.611.10482

[30] Gilbert, J.T. (1994) Choosing an Innovation Strategy: Theory and Practice. Business Horizons, 37, 16-22. http://dx.doi.org/10.1016/S0007-6813(05)80240-X

[31] Germain, R. (1996) The Role of Context and Structure in Radical and Incremental Logistics Innovation Adoption. Journal of Business Research, 35, 117-127. http://dx.doi.org/10.1016/0148-2963(95)00053-4

[32] Afuah, A. (2003) Innovation Management: Strategies, Implementation and Profits. Oxford University Press, Oxford.

[33] Drucker, P. (2014) Innovation and Entrepreneurship: Practice and Principles. Routledge, New York.

[34] Ireland, R.D., Hitt, M.A., Camp, S.M. and Sexton, D.L. (2001) Integrating Entrepreneurship and Strategic Management Actions to Create Firm Wealth. The Academy of Management Executive, 15, 49-63. http://dx.doi.org/10.5465/AME.2001.4251393

[35] Brattström, A., Löfsten, H. and Richtnér, A. (2012) Creativity, Trust and Systematic Processes in Product Development. Research Policy, 41, 743-755. http://dx.doi.org/10.1016/j.respol.2011.12.003

[36] Chemers, M. (2014) An Integrative Theory of Leadership. Psychology Press, Taylor \& Francis Group, New York.

[37] Gumusluoglu, L. and Ilsev, A. (2009) Transformational Leadership, Creativity, and Organizational Innovation. Journal of Business Research, 62, 461-473. http://dx.doi.org/10.1016/j.jbusres.2007.07.032

[38] Sosik, J.J., Kahai, S.S. and Avolio, B.J. (1998) Transformational Leadership and Dimensions of Creativity: Motivating Idea Generation in Computer-Mediated Groups. Creativity Research Journal, 11, 111-121. http://dx.doi.org/10.1207/s15326934crj1102_3

[39] Cooper, R.G. (2003) Profitable Product Innovation: The Critical Success Factors. In: Shavinina, L.V., Ed., The International Handbook on Innovation, Elsevier, Oxford, 139-157. http://dx.doi.org/10.1016/b978-008044198-6/50010-3

[40] Everse, G. (2011) Eight Communication Traps That Foil Innovation. Harvard Business Review, January 2011.

[41] McCutcheon, D.M. and Meredith, J.R. (1993) Conducting Case Study Research in Operations Management. Journal of Operations Management, 11, 239-256. http://dx.doi.org/10.1016/0272-6963(93)90002-7

[42] Voss, C., Tsikriktsis, N. and Frohlich, M. (2002) Case Research in Operations Management. International Journal of Operations \& Production Management, 22, 195-219. http://dx.doi.org/10.1108/01443570210414329

[43] Howell, J.M. and Avolio, B.J. (1993) Transformational Leadership, Transactional Leadership, Locus of Control, and Support for Innovation: Key Predictors of Consolidated-Business-Unit Performance. Journal of Applied Psychology, 78, 891. http://dx.doi.org/10.1037/0021-9010.78.6.891

[44] Elenkov, D.S. and Manev, I.M. (2005) Top Management Leadership and Influence on Innovation: The Role of Sociocultural Context. Journal of Management, 31, 381-402. http://dx.doi.org/10.1177/0149206304272151

[45] Srivastava, N. and Agrawal, A. (2010) Factors Supporting Corporate Entrepreneurship: An Exploratory Study. Vision: The Journal of Business Perspective, 14, 163-171. http://dx.doi.org/10.1177/097226291001400302 
[46] Antikainen, M.J. and Vaataja, H.K. (2010) Rewarding in Open Innovation Communities—How to Motivate Members. International Journal of Entrepreneurship and Innovation Management, 11, 440-456. http://dx.doi.org/10.1504/IJEIM.2010.032267

[47] Marques, C.S., Ferreira, J.J., Ferreira, F.A. and Lages, M.F. (2013) Entrepreneurial Orientation and Motivation to Start up a Business: Evidence from the Health Service Industry. International Entrepreneurship and Management Journal, 9, 77-94. http://dx.doi.org/10.1007/s11365-012-0243-2

[48] Martínez-Román, J.A. and Romero, I. (2013) About the Determinants of the Degree of Novelty in Small Businesses’ Product Innovations. International Entrepreneurship and Management Journal, 9, 655-677. http://dx.doi.org/10.1007/s11365-013-0269-0

[49] Locker, K. and Kaczmarek, S. (2013) Business Communication: Building Critical Skills. McGraw-Hill Higher Education, Boston.

[50] Zerfaß, A. and Huck, S. (2007) Innovation, Communication, and Leadership: New Developments in Strategic Communication. International Journal of Strategic Communication, 1, 107-122. http://dx.doi.org/10.1080/15531180701298908

[51] Linke, A. and Zerfass, A. (2011) Internal Communication and Innovation Culture: Developing a Change Framework. Journal of Communication Management, 15, 332-348. http://dx.doi.org/10.1108/13632541111183361

[52] Schroeder, R.G., Scudder, G.D. and Elm, D.R. (1989) Innovation in Manufacturing. Journal of Operations Management, 8, 1-15. http://dx.doi.org/10.1016/S0272-6963(89)80002-6

[53] Tudor, A.T., Zaharie, M. and Osoian, C. (2014) Innovation Development Needs in Manufacturing Companies. Procedia Technology, 12, 505-510. http://dx.doi.org/10.1016/j.protcy.2013.12.522

[54] Ettlie, J.E. and Rosenthal, S.R. (2011) Service versus Manufacturing Innovation. Journal of Product Innovation Management, 28, 285-299. http://dx.doi.org/10.1111/j.1540-5885.2011.00797.x 